\title{
Perspectives of application of aerated concrete for $3 D$ building printing
}

\author{
Valery Lesovik \\ Department of construction materials science, products and \\ structures \\ Belgorod State Technological University named after \\ V.G. Shoukhov \\ BSTU named after V.G. Shoukhov \\ Belgorod, Russia \\ 308012, Kostukov St., 46 \\ naukavs@mail.ru \\ Evgeny Glagolev \\ Department of Building and Urban development \\ Belgorod State Technological University named after \\ V.G. Shoukhov \\ BSTU named after V.G. Shoukhov \\ Belgorod, Russia \\ 308012, Kostukov St., 46
}

\author{
Michail Elistratkin \\ Department of construction materials science, products and \\ structures \\ Belgorod State Technological University named after \\ V.G. Shoukhov \\ BSTU named after V.G. Shoukhov \\ Belgorod, Russia \\ 308012, Kostukov St., 46 \\ mr.elistratkin@yandex.ru
}

\author{
Maksim Absimetov \\ Department of construction materials science, products and \\ structures \\ Belgorod State Technological University named after \\ V.G. Shoukhov \\ BSTU named after V.G. Shoukhov \\ Belgorod, Russia \\ 308012, Kostukov St., 46
}

\author{
Alina Ermolaeva \\ Department of construction materials science, products and structures \\ Belgorod State Technological University named after V.G. Shoukhov \\ BSTU named after V.G. Shoukhov \\ Belgorod, Russia \\ 308012, Kostukov St., 46 \\ alex.ermolaewa@yandex.ru
}

\begin{abstract}
Adaptation of the technology for a 3D building printing system aimed at producing non-autoclaved aerated concrete allows solving a task of how to create wall structures with high thermal insulation properties without using other materials, and with the increase of molding devices' productivity due to extension in layered mass. The main step towards the adaptation is the separation of the molding aerated concrete mixture into two components: basic and activating aerated processes, setting up and hardening. Mixing the components should take place in the continuous mode directly before extrusion.
\end{abstract}

Keywords - building printing, constructions with higher thermal resistence, non-autoclaved aerated concrete, composite binder, setting up control time.

\section{INTRODUCTION}

Building 3D printing or additive (layered) technologies used for erecting constructions are nowadays one of the fields of high interest among both the scientific community and representatives of small business engaged in building materials production.

This is largely due to promising perspectives appeared with building printing: time efficacy, flexibility in architectural forms and etc. [1-6]. At the same time, although there are some successful examples in Russia and abroad [712], the implementation of these technologies and their development is still at the incipient stage.

Judging by a number of publications, the main focus is on the approach how to extrude plastic mixes convergent with thermal plastic in the desktop 3D printer. The attractive feature of this approach is simplicity in technical implementation and in creating structures of complex configuration.

At the same time, there is a number of points required to be worked out: 
Firstly, there are complicated requirements to the rheology of the molding mixture and to the strength gain kinetics. On the one hand, molding mass has to be plastic to be extruded; on the other hand, it has to keep a form after having been packed into a construction and able to gain rapidly the initial strength to be load resistant when new layers will be added. As a rule, this can be solved with using a set of admixes and with excessive binder consumption that leads to a high cost in expendable materials for printing.

Secondly, in case of using non-aerated mixes for extrusion, this bets the question about the formation of required thermal technical parameters of enclosure constructions. As the solution, equipment manufacturers offer to print honeycomblike constructions with subsequent filling central holes with high-aerated materials, such as autoclaved aerated concrete. This approach demonstrates the contradiction in 3D printing ideology in terms of gaining turnkey object with the help of one device because it does not solve a problem of a thermal bypass, as opposed increases the length of displacement tracks of a molding device that results in low system productivity.

In this case, it will be feasible to draw the attention to adaptation of the technologies for the traditional materials, which have engaged a wide range of application in practice, thoroughly studied and confirmed their effectiveness. One of such materials is cellular concrete.

\section{METHODS AND MATERIALS}

Prior to adapting the aerated concrete technology to 3D printing conditions, the authors developed the baseline recipe allowing one to produce high quality materials with high marginal stability on honeycomb structure formation in conditions different from the optimal ones.

As the mineral-based binder system with flexibly adjusted properties, the composites binder was used. The efficacy of their implementation is proved and obvious for a wide range of tasks [15-20]. As an active component, the plain portlandcement CEM I $42.5 \mathrm{~N}$ was implemented, which contained $\mathrm{C} 3 \mathrm{~A}$ of $4 \%$. Its concentration in all binders amounted to $60 \%$.

The production of composites binders was carried out by means of blending finished Portland cement with the mineral powder, primarily grinned up to grinning fineness of 500 $\mathrm{m} 2 / \mathrm{kg}$. As practice showed, this method is more technological and flexible to conduct experiments.

As the mineral powders, different materials in different proportions were used, containing silica - milling slash of quartz sand and carbon materials - different-deposits limestone.

More than $100 \%$ of hemihydrates of calcium sulfate, sodium hydroxide, gas developing agent, aluminum powder, super-water reducer have been added to the mixture. The choice in favor of hemihydrates of calcium sulfate is explained with its high dispersive capacity which excludes the necessity to be milled as a binder composite. Refusal from lime carbonate in favor of sodium hydroxide is explained with the difficulties of adding it to the mixture and with its weak compatibility with a super-water reducer.

Mixing concrete ingredients with water is carried out with the hot water to provide the temperature of $38-40{ }^{\circ} \mathrm{C}$ at the moment of adding. The heat flow rate (W) for baseline materials was taken at the level of 0.43 . The order of components adding is know-how and impacts much on the outcomes.

The moment of gaining the sufficient plastic strength for aerated concrete was determined in correspondence with the capacity to resist a load placed its surface. The weight of the load is $10 \mathrm{~g}$ with the diameter of $10 \mathrm{~mm}$ that equals to 130 $\mathrm{kg} / \mathrm{m}^{2}$.

Forming all or substantially all of the constructions out of the material, to be solved by the applicant or by any other means, shall be exempted from the need to add other material to the quality of the assembler. Significantly high levels of noise and sound noise are also involved.

\section{RESULTS AND DISCUSSION}

The important preconditions to the development of the additive nature of the aerated concrete technology that can be applied to enclosure structures are as follows:

1. Formation of the whole or the most part of the construction thickness from the high aerated material is able to provide the good thermal resistance, without the necessity to use other materials as the heat retainer. The same can be said regarding to noise insulation.

2. The positive balance between the dimension of the aerated mixture placed with the molding device and the total construction dimension. In the aeration process, the material increases in its volume up to $2.5 \ldots 3$ times. Accordingly, with the same load for the molding device with the traditional and non-aerated concrete mixture, the case with the non-aerated one will be characterized with high productivity of 2 or 3 times.

3. Reduced material layer thickness to be achieved for the single run (factored in its further honeycomb process) decreases the load on the construction layers to be molded before, with the decline of their deformation and with the incline of the system productivity.

4. Reduced thermal conduction of aerated systems enables heat leveraging of the exothermic reactions in binders to accelerate the hydration processes.

At the same time, there are some difficulties, among them:

1. Lower strength parameters of honeycomb structures as compared with compact ones. With ensuring the strength level, the molded in layers aerated concrete, the factor mentioned-above can not be a serious limit because, as compared with honeycomb constructions printed with highstrength fine-grained concrete, the square of the cross-section area in solid walls is many times more and able to take loads typical to a low-rise building.

2. Poor hypothetical adaptability of aerated mixtures to printing constructions of complex configuration. 
3. The necessity to ensure the protection for a molded mixture to be binned into a molded device, up to the full its runout and blowing out after layering down into a construction.

The key measure for the aerated concrete technology to be adapted to the building printing is, to our mind, the division of molding mass into two:

- the basic one - a solution containing the key components but not capable of full-fledged spontaneous aeration;

- activating - ensuring a sustainable gas release reaction and fixation of the aerated structure to be gained.

Mixing the two compositions should be running in the honeycomb device of the building 3D printer before layering the mass in a construction where blowing out occurs. This approach allows bringing into line the technical requirements to the operation of layered molding with physico-chemical processes running in molding mass, without significant complications in terms of technology and of budget expansion.

The different schemes on how to implement the approach were trialed experimentally, among them there are the most perspective:

Scheme \#1. The extrusion some part of water from the molding mass and the aerated component, with the temperature fixation at the level of $20 \ldots 30^{\circ} \mathrm{C}$, that allows one to save (reducibility) its basic properties for $30 \mathrm{~min}$, considered as significant to use the mixture reservoir in the molding device. The activation of the blowing out process is done due to adding the gassing agent suspension, desirably in the hot condition, by mixing. Laying should be done in thin layers, in order to heat up, the authors used infrared lights which provide the heating of the molding mass up to $40 \ldots 45^{\circ} \mathrm{C}$ for $20 \ldots 40 \mathrm{sec}$.

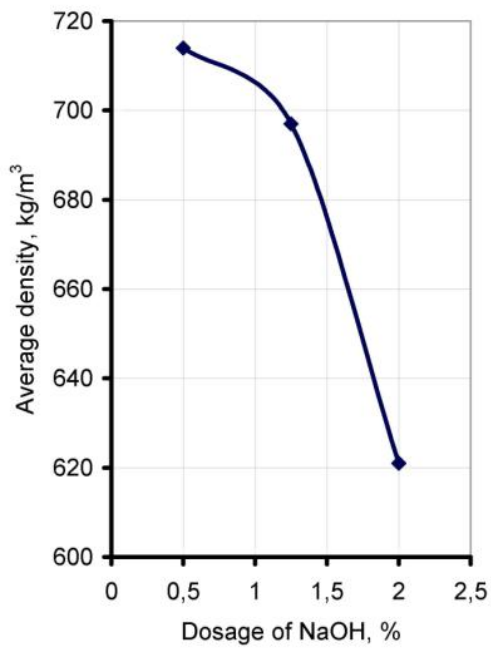

Fig. 1. Dependence of the properties of aerated concrete on the amount of sodium hydroxide

Scheme \#2. The extrusion of some part of water and alkaline component $\mathrm{NaOH}$ from the basic molding mass. The obtained mixture with temperature of $20 \ldots 25^{\circ} \mathrm{C}$, and containing a gassing agent, had adoptable consistency and was suited to with the activator during $25 \ldots 30 \mathrm{~min}$. In addition to the above there was observed spontaneous mass growth not more than $5 \ldots 10 \%$ to the end of holding time. To our opinion this can not be the obstacle to using this scheme in practice. Probably, the gas bubble agents in the mixture up to the moment of activator adding influence positively the dynamics of aeration process. The mixture activation was carried out by blending it with consequent adding hot water and the required dose of the hot sodium hydroxide composite. As a result, the mixture reached the temperature of $40 \ldots 45^{\circ} \mathrm{C}$, fully reactivated its fluidity and was blown out during $5 \ldots 8 \mathrm{~min}$.

The influence of $\mathrm{NaOH}$ dosage on the density of aerated concrete is shown in Fig. 1. As seen in the graph, the intensive density fall starts after passing the point $1 \%$ of sodium hydroxide from the mass of the composite binder. The increase of the dosage up to $2 \%$ is fostering the aeration process, making it less dependent on adverse external factors. At the same time the probability of bloom occurrence on the surface of the molded construction in exploitation and due to potential negative influence of alkali on organic decorative composites. In order to conduct further experiments, the dose for alkali activator as $1 \ldots 1.5 \%$ was defined.

The important disadvantage of the composites to be developed is a long time of setting up and a low speed of initial strength gaining, needed to fix the structure and to make further layers. The division of the molding mass into two parts allows one to use powerful setting up intensifiers, for instance, sodium hydrocarbonate (soda), adding of which in traditional order, when the mixture is prepared, is very complicated due to quick gelatinizing. The other trialed approach is adding the limited amount of calcium sulfate into the systems at the level of adding the binder.

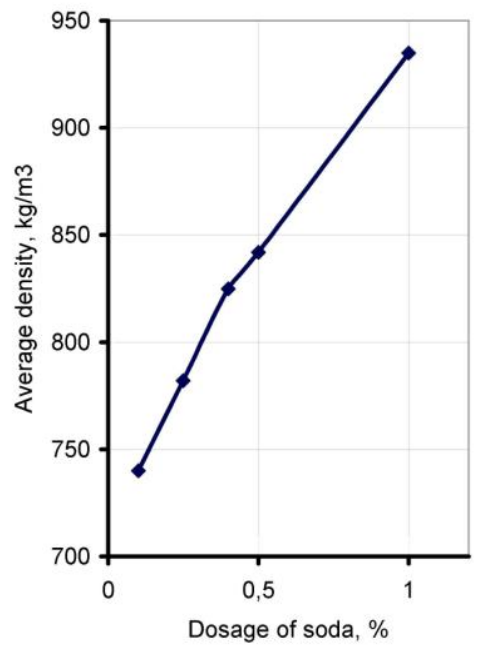

Fig. 2. Dependence of the properties of aerated concrete on soda dosage

As seen in the graphs (fig. 2, 3), the amount of adding the intensifier is apparently reflected lineally on the average density and setting up time of the aeration. During the active aeration phase for $5 \ldots 7 \mathrm{~min}$, after the intensifier is added, the setting up time is due to be not less $10 \mathrm{~min}$ that is equal to the 
soda dosage, not more than $0.7 \%$ from the composite binder mass.

With the average density non-aerated molding mixture of $2300 \mathrm{~kg} / \mathrm{m}^{3}$, the mentioned supportability defined before, allows one to place layers from $5 \ldots 5.5 \mathrm{~cm}$. After blowing out, this is able to form the material layer from $10 \ldots 15 \mathrm{~cm}$ (depending on the average density).

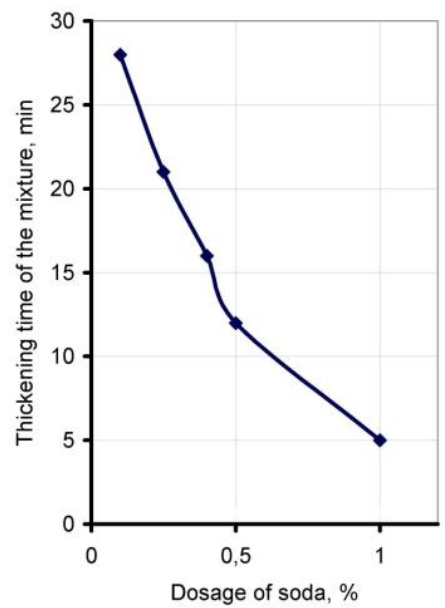

Fig. 3. Lifetime of the mixture depending on the dosage of soda

The main problem to add gypsum into the concrete composites is the threat of ettringite formation, leading after the fall in strength or complete material breakage. In this case, it is proposed to use Portland cement. The calcium sulfate is proposed to add in small amounts to achieve the quick increase in the mixture plasticity strength. The essential difference from the composite calcium sulfate-based binders is the lack of active minerals to be added separately. In order to prevent the destructive intrusions, let us propose using the sulfate-resistant Portland cement with minerals instead of the traditional Portland cement.

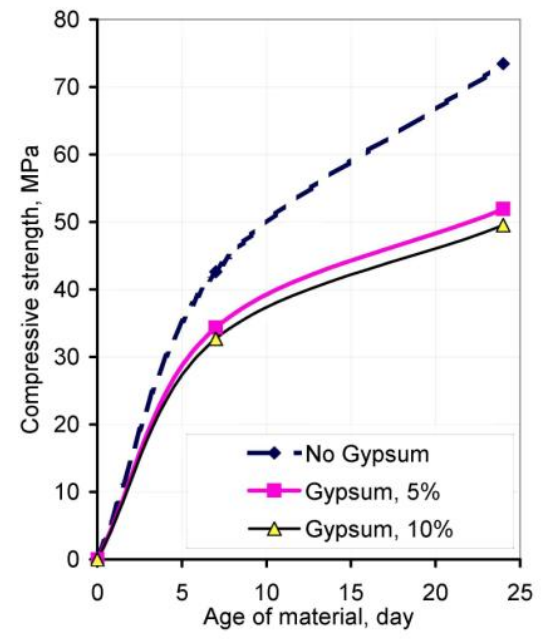

Fig. 4. The rate of curing strength CEM I, depending on the dosage of gypsum

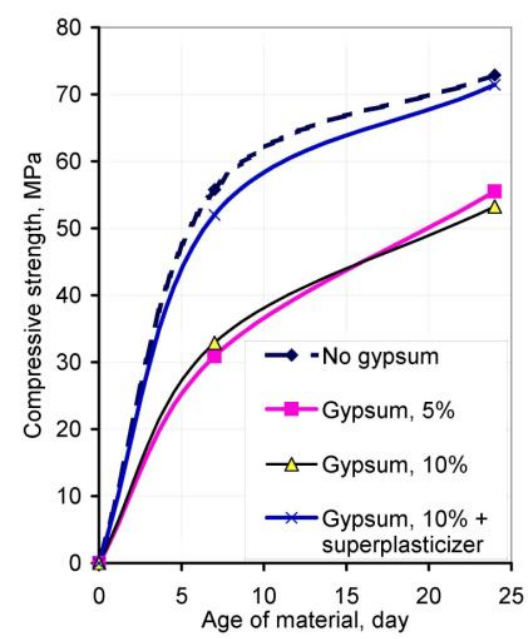

Fig. 5. Velocity of strength of sulfate-resistant cement depending on the dosage of gypsum

The samples have been produced and trialed in different Portland cement composites: the traditional one, CEM I, and sulfate-resistant one with minerals. They were added 5 and $10 \%$ of the building gypsum. The results are illustrated in fig. 4 and 5.

The gypsum-free composites had the standard setting up time for cement systems and the standard kinetics of strength gaining. Gypsum adding in described dosages considerably reduces the strength parameters in composites, namely the grade strength up to $25 \ldots 30 \%$, which is either linked with the fall in cement concentration in the blended binder or with its negative impact on structure-formation processes.

It becomes noticeable that the speed of the strength gaining with gypsum apparently does not depend on the later. The possible reason for these phenomenon is the ettringite system as in the initial form and in the secondary one as well. The formation of the initial ettringite does not entail the tangible reduction in strength, the evidence of which is relatively high value of the strength ( 7 days) $80 \%$ from the control composite for the supplements free cement. The transmission of one part of the initial ettringite into the secondary one slows down the strength gaining process, which is justified in lower deflection angle in curves, fig. 4 .

In case of sulfate-resistant cement, this fact is considerably less due to less favorable conditions for ettringite transmission that is explained by the adhesion of lime carbonate with mineral (fig.5). The initial ettringite probably impacts the reinforcement action on the lime carbonate stone increasing its strength. The evidence of it is the samples images that have been trialed in the press (figure 6). The degree of their mechanical deformation fell drastically as the level of gypsum dosage increased, whereas the load-carrying capacity was completely lost. 


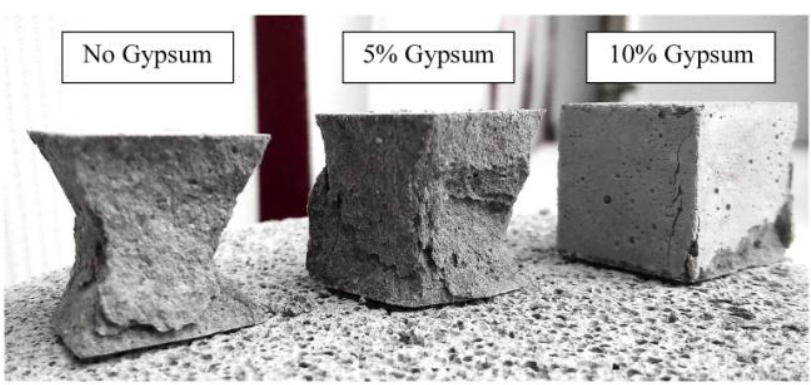

Fig. 6. Appearance of samples based on sulfate-resistant Portland cement after destruction

Within the considered algorithm, the possibility to use other supplements effectively is real.

\section{SUMMARY}

The results are the ground to assume that the use of aerated building materials in building printing is possible and reasonable. Currently the authors develop a molding device capable of being used with aerated concrete for laboratory building printer. Here, the serious technical problem is high initial flowability of the molding mixture, which is quickly lost in the blowing out process, and when the intensifier of setting up takes effect. In the authors' opinion, there is the need to equip the molding devices with the sliding supportive screens, preventing from the initial mixture spreading in the zone of transporting out and blowing out. In addition, to achieve this goal, the adjustments in rheological characteristics can be applied, such as the increase in the flowability level that can be done with the choice of the rational mineral in the composite binder.

\section{Acknowledgment}

The research is conducted in the framework of the Program of Flagship University Development on the basis of Belgorod State Technological University named after V.G. Shoukhov, using equipment of the High Technology Center at BSTU named after V.G. Shoukhov.

\section{References}

[1] Y.W. Tay, B. Panda, S.C. Paul, K.F. Leong, C.K. Chua, "Processing and properties of construction materials for 3D printing," Materials Science Forum, vol. 861, pp. 177-181, 2016.

[2] A. Perrot, D. Rangeard, A. Pierre, "Structural built-up of cement-based materials used for 3D printing extrusion techniques," Materials and Structures. Materiaux et Constructions, vol. 49(4), pp. 1213-1220, 2016.

[3] M.V. Savytskyi, S.V. Shatov, O.A. Ozhyshchenko, "3D-printing of build objects," Bulletin of Pridneprovsk State Academy of Civil Engineering and Architecture, vol. 3(216), pp. 18-26, 2016.
[4] S.M. Zyhulia, "Present state and analysis of surface plastic deformation in the printing machine building," Technology and Printing Technology, vol. 2(40), pp. 69-82, 2013.

[5] S.Stavridi, "Reforming abstract geometrical ideas through 3D printing: A proposal for experiential e-Making technology in creative education. ISEC 2017." In Proceedings of the 7th IEEE Integrated STEM Education Conference, 7910218, pp. 10-16, 2017.

[6] S. Rouleau, M. Cazes, R. Dupont, T. Benadda, S.V.V. Piazza, "Using 3D printing to help people living with Ataxia," In the Proceedings of Conference on Human Factors in Computing Systems, pp: 14-19, 2016.

[7] J. Šafka, M. Ackermann, J. Bobek, J. Habr, L. Běhálek, "Use of composite materials for FDM 3D-print technology," Materials Science Forum, vol. 862, pp. 174-181, 2015.

[8] S. Junk, S. Schrock, "New developments in design education for additive manufacturing. Proceedings of the $18^{\text {th }}$ International Conference on Engineering and Product Design Education: Design Education," Collaboration and Cross-Disciplinarity, E and PDE, pp. 290-295, 2016.

[9] S. Allameh, "On the development of a 3D-printer for combinatorial structural composite research," ASME International Mechanical Engineering Congress and Exposition, Proceedings (IMECE), vol. 3, pp. 150-157, 2015.

[10] D. Günther, B. Heymel, J.F. Günther, I. Ederer, "Continuous 3Dprinting for additive manufacturing," Rapid Prototyping Journal, vol. 20(4), pp. 320-327, 2015.

[11] P. Liu, R. Farzana, R. Rajarao, V. Sahajwalla, "Lightweight expanded aggregates from the mixture of waste automotive plastics and clay," Construction and Building Materials, vol. 145, pp. 283-291, 2016.

[12] Q. Li, I. Kucukkoc, D.Z. Zhang, "Production planning in additive manufacturing and 3D printing," Computers and Operations Research, vol. 83, pp. 1339-1351, 2016.

[13] Y. Fu, X.A. Cao, Z. Li, "Printability of magnesium potassium phosphate cement with different mixing proportion for repairing concrete structures in severe environment," Key Engineering Materials, vol. 711, pp. 989995, 2016.

[14] V.S. Lesovik, L.H. Zagorodnjuk, N.I. Chernysheva, E.S. Glagolev, A.S. Kucherov, M.Y. Drebezova, E.V. Kaneva, "Modern three-dimensional technology and factors limiting their," Bulletin of BSTU named after V.G. Shukhov, vol. 12, pp. 22-30, 2016.

[15] R. Lesovik, Y. Degtev, M. Shakarna, A. Levchenko, "Green composites in architecture and building material science," Modern Applied Science Journal, vol. 9(1), pp. 45-50, 2015.

[16] A.A. Kuprina, V.S. Lesovik, L.H. Zagorodnyk, M.Y. Elistratkin, "Anisotropy of materials properties of natural and man-triggered origin," Research Journal of Applied Sciences, vol. 9(11), pp. 816-819, 2014.

[17] N.I. Alfimova, E.E. Shadskiy, R.V. Lesovik, M.S. Ageeva, "Organicmineral modifier on the basis of volcanogenic-sedimentary rocks," International Journal of Applied Engineering Research, vol. 10(24), pp. 45131-45136, 2015.

[18] Y.M. Bazhenov, V.T. Erofeev, V.I. Rimshin, S.V. Markov, V.L. Kurbatov, "Changes in the topology of a concrete porous space in interactions with the external medium," Engineering Solid Mechanics Journal, vol. 4(4), pp. 219-225, 2016.

[19] V.V. Nelyubova, V.V. Strokova, A.B. Buchalo, "Non-autoclaved cellular composites with nanocomponents: Composition, structure, properties," Saarbrucken, pp. 565-572, 2017.

[20] M.N. Sivalneva., N.V. Pavlenko, P.P. Pastushkov, V.V. Strokova, D.D. Netsvet, N.A. Shapovalov, "Steam curing characteristics of cellular concrete on the base of nanostructured binder," Journal of Fundamental and Applied Sciences, vol. 8(38), pp. 1480-1488, 2016 